\title{
Changes in clinical and biochemical characteristics of polycystic ovary syndrome with advancing age
}

\author{
Sebastião Freitas de Medeiros ${ }^{1,2}$, Márcia Marly Winck Yamamoto², Matheus Antônio Souto de Medeiros², \\ Bruna Barcelo Barbosa ${ }^{2}$, José Maria Soares Junior ${ }^{3}$ and Edmund Chada Baracat ${ }^{3}$ \\ 1Department of Gynecology and Obstetrics, Medical School, Federal University of Mato Grosso, Cuiabá, Mato Grosso, Brazil \\ ${ }^{2}$ Tropical Institute of Reproductive Medicine, Cuiabá, Mato Grosso, Brazil \\ ${ }^{3}$ Disciplina de Ginecologia, Departamento de Obstetrícia e Ginecologia, Hospital das Clínicas, Faculdade de Medicina da Universidade de São Paulo, São \\ Paulo, São Paulo, Brazil \\ Correspondence should be addressed to S F de Medeiros: de.medeiros@terra.com.br
}

\begin{abstract}
Objective: To verify whether aging can modify the clinical and biochemical characteristics of women with polycystic ovary syndrome (PCOS).

Material and methods: This observational cross-sectional study was conducted at the reproductive endocrinology clinics of Julio Muller University Hospital and Tropical Institute of Reproductive Medicine in Cuiabá, MT, Brazil, between 2003 and 2017. Both, 796 PCOS and 444 non-PCOS normal cycling women underwent the same examination. PCOS was diagnosed using the Rotterdam criteria as recommended for adolescent and adult subjects. Anthropometric, metabolic, and endocrinological modifications with aging were initially examined in the two groups: control and PCOS. Further analyses were performed after a 5-year age stratification of data throughout the reproductive period. All participants signed a consent form approved by the local ethical committee. Results: Biomarkers of adiposity were more remarkable in African descendant PCOS women. Body weight, waist/hip ratio, fat mass, and BMI were higher in PCOS women and tended to increase at all 5 age-strata, between $\leq 19$ and 35 years of age. Serum androgen levels decreased with aging, markedly in PCOS subjects $(P<0.01$ for all agestrata comparisons), but remained elevated when compared with the levels found in controls. Carbohydrate markers, triglycerides, and total cholesterol tended to increase over time in PCOS $(P<0.01$ for all age-strata comparisons). Total cholesterol also tended to increase with age in non-PCOS women $(P=0.041)$.

Conclusion: The present study has shown that the advancing age influences many features of PCOS women. Biochemical hyperandrogenism, the core criterion recommended in the current systems to define the syndrome, showed statistically significant tendencies to decrease with aging progression but did not normalize. The use of age-adjusted features for the diagnosis of PCOS are recommended.
\end{abstract}
Key Words
- polycystic ovary syndrome
- age groups
- body weight changes
- endocrine trends
- biological aging

\section{Introduction}

Polycystic ovary syndrome (PCOS) has a prevalence ranging from 5 to $20 \%$ in women of reproductive age, depending on the population and criteria used for making a definitive diagnosis $(1,2)$. The use of ultrasound may increase PCOS prevalence by two to threefold and adds two more phenotypes (1). As the criteria used for the diagnosis https://ec.bioscientifica.com https://doi.org/10.1530/EC-19-0496 (c) 2020 The authors Published by Bioscientifica Ltd
Endocrine Connections (2020) 9, 74-89 
of PCOS may decrease, or even normalize, during the reproductive lifetime, the prevalence of PCOS seems to decrease with age (2). The elapsed time for the appearance of a particular characteristic since the disease first appears is unknown. Menses abnormalities, polycystic ovary morphology, and hyperandrogenism, the most important features of PCOS that may even advance menarche, might change with age (3).

Biochemical hyperandrogenism, the clue criterion for the diagnoses of PCOS, seems to decrease with aging and this is an important issue in the clinical practice $(1,4,5,6)$. According the Rotterdam criteria, the ovarian morphology, or size, is also important for PCOS diagnoses, and it is known that the ovary reaches its maximum volume at 1.2-3.8 years after menarche (7). In addition, the elapsed time for the ovaries acquiring the classic PCOM was not determined and, despite some controversy, it may vary among individuals and/or according to androgen levels $(8,9)$. It was shown that PCOM becomes more prevalent after 20 years of age (10). Therefore, for adolescents, only ovarian volume is used (11). Regarding menstrual cycle intervals or amenorrhea as results of oligo or anovulation (12), several studies, but not all, have reported a tendency for cycle normalization to occur with age, mainly in those women older than 30 years $(13,14,15,16,17,18)$. Thus, despite the worsening of metabolic parameters, the ovulatory function seems to improve in PCOS patients with advancing age as a consequence of the decrease in the follicle population $(10,12,13,19,20,21)$.

Because of these potential drawbacks, it was recently recommended that clinicians should pay close attention to practice guidelines regarding screening, diagnostic assessment, and life-stage for irregular menses or ovulatory dysfunction, clinical and biochemical hyperandrogenism for a definitive diagnosis of PCOS $(12,14)$. Therefore, because clinical, biochemical, and endocrine characteristics may change over time and cause some difficulties when attempting to standardize a PCOS diagnosis at different ages (22), the application of a notyet-established, age-adjusted criterion would be useful (2).

It is worth noting that, in addition to the possible modifications in the established criteria to diagnose PCOS with aging, other concurrent abnormal condition may also change with the aging process in PCOS subjects. Modifications in anthropometric parameters with advancing age may occur but the studies are scarce at this time $(1,4,18,23)$. Regarding lipids, total cholesterol (TC), low-density lipoprotein cholesterol (LDL-C), and triglycerides (TG) were reported to increase with aging in women with PCOS $(4,10,15)$. Furthermore, carbohydrate metabolism markers may also change with age in PCOS women $(4,15,18,24)$. Despite design limitations, longitudinal $(17,18)$ and cross-sectional studies $(13,15$, $16,19,21,24)$ have shown similar results.

For the reason that the majority of available data on the association of advancing age with PCOS characteristics enrolled a small sample size, they were stratified in very few strata and included a limited number of variables, the present study aims to boost and expand the current knowledge by assessing association of advancing age with the clinical, anthropometric, metabolic, and hormone characteristics of a large number of women with PCOS. In parallel, the same variables were compared and controlled with data obtained from non-PCOS normal cycling women in the same age period.

\section{Materials and methods}

\section{Design, objective, and subjects eligibility}

This observational cross-sectional study aimed to assess the influence of advancing age on clinical and biochemical features of PCOS women, and the study included 796 women with PCOS and 444 non-PCOS normal cycling controls whom were seen the general and endocrinology clinics at Julio Muller University Hospital and the Tropical Institute of Reproductive Medicine in Cuiabá, MT, Brazil, between 2003 and 2017. The study was approved by the Ethical Committee of the School of Medical Sciences, Federal University of Mato Grosso, Brazil. Women who reported infertilities at one of the two Institutions whose final diagnosis was male or tubal infertility were included as control; all participants have signed a written consent form. PCOS and non-PCOS women were $27.4 \pm 5.2$ years and $29.3 \pm 4.7$ years of age, respectively $(P<0.001)$. In the control group, 393 women were Caucasian, 27 black, and 24 of other races. In PCOS, 580 were Caucasian, 106 were black, and 110 of other races. For comparisons, non-PCOS normal cycling women were referred to the same protocol, including the endovaginal ultrasound to determine ovarian size and/or morphology. Follicle count was not reported because ultrasound was performed by different examiners and different machines over time. In addition, this parameter should not be used to define PCOM in adolescent PCOS $(11,25)$.

Classic 21-hydroxylase, 3 3 -hydroxysteroide

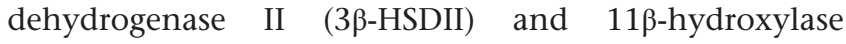
deficiencies were excluded in the cases of 17-hydroxyprogesterone (17-OHP4) levels $\leq 5 \mathrm{ng} / \mathrm{mL}$ ( $\leq 15 \mathrm{nmol} / \mathrm{L}), \quad$ 17-hydroxypregnenolone (17-OHPE) 
$<0.42 \mathrm{ng} / \mathrm{mL}(<13.5 \mathrm{nmol} / \mathrm{L})$, and compound $\mathrm{S}<0.8 \mathrm{ng} / \mathrm{mL}$ $(<23 \mathrm{nmol} / \mathrm{L})(26,27)$. Primary hypothyroidism was excluded by a thyroid-stimulating hormone (TSH) level of $\leq 4.2 \mu \mathrm{UI} / \mathrm{mL}$ and free thyroxin (fT4) level of $\leq 9.0 \mathrm{pmol} / \mathrm{L}$ $(28,29)$. Hyperprolactinemia was excluded when prolactin (PRL) levels were $\leq 1.1 \mathrm{nmol} / \mathrm{L}$ (30). Before analysis PCOS patients were also stratified in categories according to age, as follows: younger than 19 years, 20 to 24 years, 25 to 29 years, 30 to 34 years, 35 to 39 years. Infertile women presenting normal ovulatory cycles who had non-ovarian (male or anatomical factors) cause of infertility were included as controls. Both, controls and PCOS patients who had used sex steroids or insulin-sensitizing drugs over the past 6 months or those who did not fulfill the Rotterdam criteria were excluded.

\section{Definitions}

In the adolescent group, the diagnosis of PCOS was defined by the presence of all three Rotterdam criteria (31). In adults, women older than 19 years, PCOS was diagnosed using at least two of the Rotterdam criteria (1). Normal menstrual cycle was defined by menstrual interval between 26 and 34 days. Amenorrhea was defined by the absence of menstrual period for $\geq 90$ days. Frequent menses were defined as more than four menstrual episodes in a 90-day period, and infrequent menses were defined as menstrual cycle $\geq 45$ days or $\leq 8$ menstrual period in the past year $(14,32,33)$. Biochemical hyperandrogenism was defined by at least one of the following criteria: total testosterone $\geq 2.1 \mathrm{nmol} / \mathrm{L}$, free testosterone (FT) $\geq 0.03 \mathrm{pmol} / \mathrm{L}$, dehydroepiandrosterone sulfate (DHEAS) $\geq 6.7 \mu \mathrm{mol} / \mathrm{L}$, androstenedione (A4) $\geq 8.6 \mathrm{nmol} / \mathrm{L}$, and free androgen index (FAI) $\geq 6$ (27). Impaired fasting glucose (IFG) was defined by fasting plasma glucose concentration $>100 \mathrm{mg} / \mathrm{dL}(5.5 \mathrm{mmol} / \mathrm{L})$ or $<126 \mathrm{mg} / \mathrm{dL}$ (7.0 mmol/L). Glucose intolerance (GI) was defined by a glucose concentration $\geq 7.8 \mathrm{nmol} / \mathrm{L}$ at $120 \mathrm{~min}$ after the ingestion of dextrose. Insulin resistance (IR) was defined by fasting insulin levels of $>12.2 \mu \mathrm{U} / \mathrm{mL}(84.7 \mathrm{pmol} / \mathrm{L})$ (34) and/or a HOMA-IR value of $\geq 2.7$ (35). Type 2 diabetes mellitus (T2DM) was defined as fasting plasma glucose $\geq 126 \mathrm{mg} / \mathrm{dL}(7.0 \mathrm{mmol} / \mathrm{L})$ or glucose $\geq 200 \mathrm{mg} / \mathrm{dL}$ $(11.1 \mathrm{mmol} / \mathrm{L})$ at $120 \mathrm{~min}$ after the ingestion of dextrose.

\section{Clinical and ultrasound evaluation}

Standardized clinical screening included menstrual and reproductive history, measurements of blood pressure, presence of acne, hirsutism, and/or acanthosis nigricans, and anthropometric measurements. All data were registered in a template used in both institutions but in some participants a few observations were not recorded. Systolic blood pressure (SBP) and diastolic blood pressure (DBP) were measured with the study participants in a sitting position after at least 5 min of resting. Because inconsistent results due to ethnicity and inter-rater evaluation, the Ferriman-Gallwey score was not used and the clinical hyperandrogenism was registered as dichotomous variable, according to the patient's complaints and the presence or the lack of hirsutism in the upper lip, chin, chest, upper or lower back, upper or lower abdomen, upper arms and thighs $(27,36)$. Ovarian morphology was examined by ultrasonography, using a vaginal transducer with a frequency of $5-8 \mathrm{MHz}$ (Toshiba Xario SSA-660A, Toshiba Medical do Brazil LTDA, Taboão da Serra, SP, Brazil or Voluson ${ }^{\circledR}$ E8, GE Health Care, United Kingdom). Antral follicle count $\geq 12$ follicles in at least one ovary and ovarian volume $\geq 10 \mathrm{~cm}^{3}$ were taken for assuming PCOM. The ovarian volume was calculated by the ellipsoid formula: $\pi / 6 \times \mathrm{D} 1 \times \mathrm{D} 2 \times \mathrm{D} 3$, where D1, D2, and D3 were taken as the maximum diameters (37). The ovarian volume was calculated as the mean value of the left and right ovary volumes.

\section{Anthropometric measures}

The subjects were weighed on an electronic scale and height was measured using a Harpenderstadiometer (Holtain Ltd., Crymych, Dyfed, UK). WC was measured at the midway point between the lower rib margin and the iliac crest, while the hip was measured at the widest circumference of the greater trochanters and the waisthip ratio (WHR) was obtained by dividing the WC by the hip circumference. BMI was calculated as body weight in kilograms divided by height in meters squared. Lean body mass (LBM) was calculated using the James equation, as follows: $[1.07 \times$ weight $(\mathrm{kg})]-148 \times[$ weight $2 /(100 \times$ height $(\mathrm{m})] 2$. Fat mass $(\mathrm{FM})$ was calculated as body weight minus LBM. The visceral adiposity index (VAI) was estimated using the following equation: $\mathrm{WC} /[36.58+(1.89 \times \mathrm{BMI})] \times(\mathrm{TG} / 0.81) \times(1.52 / \mathrm{HDL}-\mathrm{C})$ (38). Lipid accumulation product (LAP) was calculated as $[\mathrm{WC}(\mathrm{cm})-58] \times[\mathrm{TG}(\mathrm{mmol})]$ as established for women (39).

\section{Biochemical and metabolic measurements}

Blood samples were taken by cubital venipuncture between 7:30 and 10:00 $\mathrm{h}$, after 10-12 $\mathrm{h}$ of fasting, between the third and fifth days of a spontaneous menstruation or,

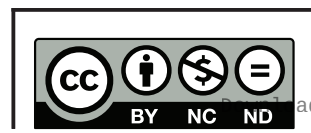

This work is licensed under a Creative Commons Attribution-NonCommercial-NoDerivatives 4.0 enternationab bicense.ifica. com at 04/26/2023 09:55:10AM 
in the case of infrequent menses or amenorrhea, on any day regardless of the time elapsed since the last menstrual period; in this case, the progesterone ( $\mathrm{P} 4$ ) level was used to certify that samples were collected in the follicular phase and the results were validated whenever the P4 level was lower than $6.3 \mathrm{nmol} / \mathrm{L}$ (30). A glucose oxidase technique (Beckman Glucose Analyses, Fullerton, CA, USA) was used to measure fasting glucose. For the oral glucose tolerance test (OGTT), blood samples were collected at 0 , $30,60,90,120$, and $180 \mathrm{~min}$ after the ingestion of $75 \mathrm{~g}$ of dextrose for the measurement of plasma glucose and insulin levels (40). Glycated hemoglobin was measured using the turbidimetric assay (Wiener Laboratories, Rosario, Argentina). Homeostatic Model Assessment of Insulin Resistance (HOMA-IR) and HOMA \% B were calculated using the free HOMA 2 calculator software (Diabetes Trials Unit, Oxford, UK) (41). Triglycerides (TG), high-density lipoprotein cholesterol (HDL-C) and total cholesterol (TC) were measured after a 12-h overnight fast using an enzymatic assay (Wiener Laboratories, Rosario, Argentina). Low-density lipoprotein cholesterol (LDL-C) was calculated as TC $-(\mathrm{HDL}-\mathrm{C}+\mathrm{TG} / 5)(42)$.

\section{Hormone measurements}

Serum thyroid-stimulating hormone (TSH), estradiol (E2), prolactin (PRL), sex-hormone-binding globulin (SHBG), total testosterone, DHEA, and free thyroxin (FT4) were measured with an electrochemiluminescence assay (Elecsys 1010, Roche Diagnostics GmbH). The intra- and inter-assay coefficients of variation were lower than 10\% for all analytes. Serum P4 was measured using a chemiluminescence assay (Advia Centaur, Siemens Healthcare Diagnostics, UK) with a sensitivity of $0.7 \mathrm{nmol} / \mathrm{L}$, coefficients of intra- and inter-assay variation were lower than 12 and 4\%, respectively. A4, DHEAS, cortisol (F), and insulin were measured using a chemiluminescence assay with a sensitivity of $1.0 \mathrm{nmol} / \mathrm{L}$, $0.1 \mu \mathrm{mol} / \mathrm{L}, 0.2 \mathrm{nmol} / \mathrm{L}$, and $2 \mu \mathrm{UI} / \mathrm{mL}$, respectively (Siemens Medical Solution Diagnostics); the intra- and inter-assay oefficients of variation were 6.4 and $8.2 \%$ for A4; 4.9 and $8.8 \%$ for DHEAS; 5.8 and $8.6 \%$ for F; and 4.9 and $6.4 \%$ for insulin. Free testosterone (FT) concentrations were measured using a free testosterone ELISA kit (GenWay Biotech Inc., CA, USA), with a sensitivity of $0.6 \mathrm{pmol} / \mathrm{cL}$. The intra- and inter-assay coefficients of variation ranged from 5 to $10 \%$ and 8 to $12 \%$, respectively. 17-OHP4 levels were verified using a coat-a-count RIA (Siemens Health Care Diagnostics Inc.) with a sensitivity of $0.7 \mathrm{nmol} / \mathrm{L}$, and an inter- and intra-assay imprecision of 5.5 and
$7.9 \%$, respectively. FAI was calculated as the testosterone $(\mathrm{nmol} / \mathrm{L}) / \mathrm{SHBG}(\mathrm{nmol} / \mathrm{L}) \times 100$. Free estrogen index $(\mathrm{FEI})$ was estimated as $100 \times \mathrm{E} 2 \mathrm{pmol} / \mathrm{L} / 272.14 \times \mathrm{SHBG}(43)$.

\section{Statistical analysis}

After the exclusion of outliers using the Grub's test, the distribution was assessed using the Shapiro-Wilk test and those with a non-Gaussian distribution were transformed. The skewed data were linearized using a logarithmic or square transformation according to the best fit. Prior to the analysis, the data were back-transformed into the original units. The results of continuous variables are presented as the mean and S.D. and nominal variables are expressed as number and percentages. Differences between two proportions were examined using the $\mathrm{Z}$ test. Differences between two continuous variables were determined using the Student $t$ test because equal variances were found using the Levene's test. Differences among more than two Gaussian variables were determined using one-way ANOVA followed by Tukey post hoc test. After stratification of age into the 5-year categories, the age-strata were analyzed as a discrete variable and the tendency of proportions to change with advancing age was verified using the Cochran-Armitage Trend test. After adjustment for BMI, the tendency of each anthropometric, metabolic and hormonal variable to change with advancing age was assessed using one-way analysis of covariance (ANCOVA) followed by the Bonferroni post hoc test. All of the statistical procedures were performed using the Statistical Package for the Social Sciences, software program, version 17 (IBM Corp.) and GraphPad Prism, version 4 for Windows, GraphPad Software, Santiago, CA, USA. All tests were two-sided and $P$ values $<0.05$ were considered to be statistically significant.

\section{Results}

Taking in account the Rotterdam criteria, prevalences and characteristics of the four different PCOS phenotypes are shown in Table 1. As a whole group, PCOS patients were significantly younger than the controls $(27.4 \pm 5.2$ vs $30.1 \pm 4.6$ yo, $P=0.001$ ), with a difference between the means of less than 2 years. However, the average of ages in each 5-year age stratum was similar in PCOS and non-PCOS subjects. The comparisons of each age stratum between non-PCOS normal cycling controls and PCOS patients were as follows: $\leq 19$-years stratum, non-PCOS $(n=10, \quad \bar{x}=16.2 \pm 2.0) \quad$ vs $\operatorname{PCOS}(n=60, \quad \bar{x}=16.6 \pm 2.0)$

This work is licensed under a Creative Commons Attribution-NonCommercial-NoDerivatives 4.0 Internationab License.ifica . com at 04/26/2023 09:55:10AM 


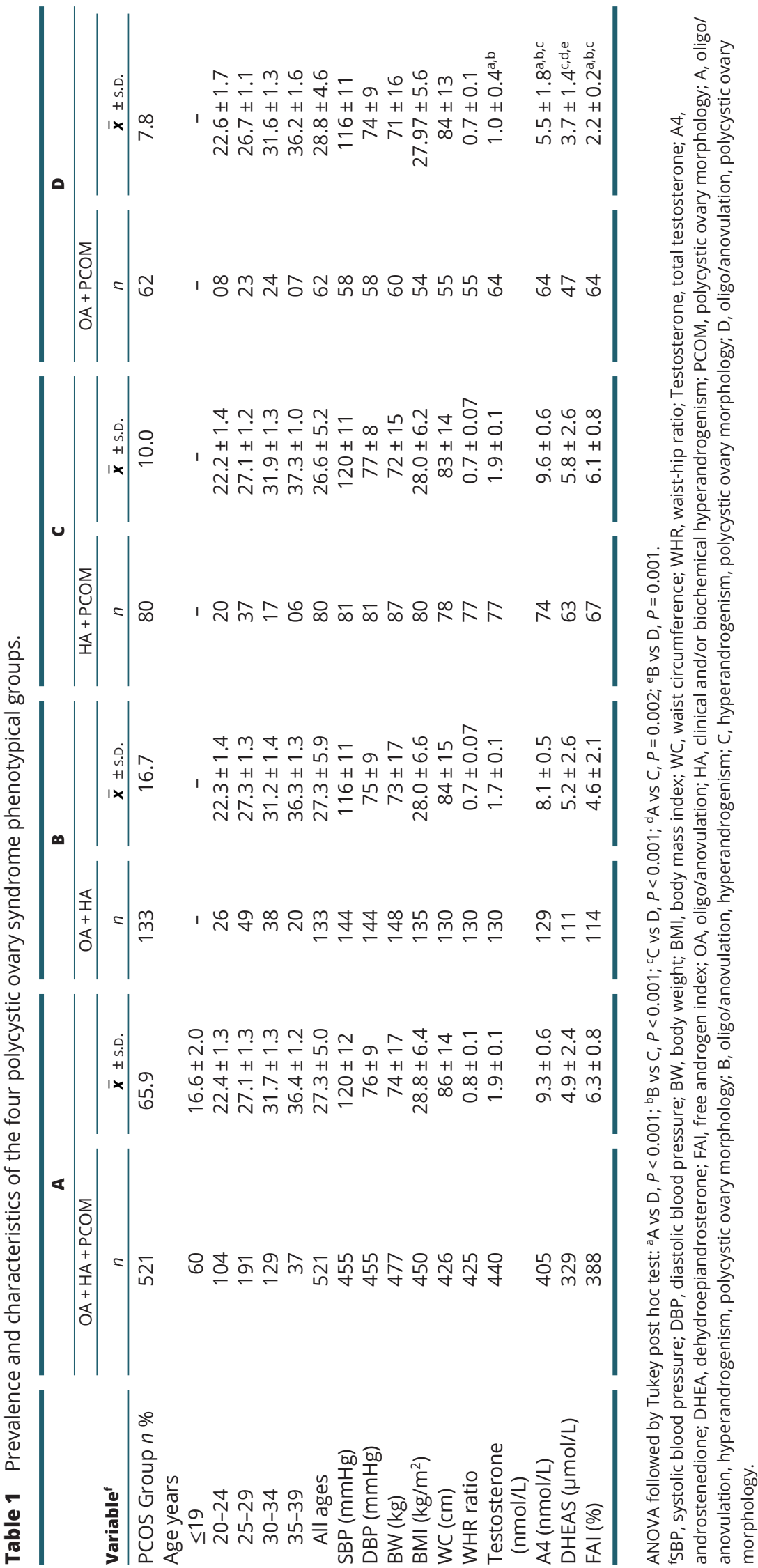


$(P=0.008) ; \quad 20-24$ years stratum, non-PCOS $(n=41$, $\bar{x}=22.6 \pm 1.3) \quad$ vs $\quad(n=158, \quad \bar{x}=22.3 \pm 1.4) \quad(P=0.157)$, 25-29 years stratum, non-PCOS $(n=137, \bar{x}=27.2 \pm 1.4)$ vs PCOS $(n=301, \bar{x}=27.1 \pm 1.3)(P=0.570)$. 30-34 years stratum, non-PCOS $(n=171, \bar{x}=39.1 \pm 1.4)$ vs $P C O S=207$, $\bar{x}=31.6 \pm 1.3)(P=0.061) ; 35-39$ years stratum, non-PCOS $(n=85, \quad \bar{x}=36.3 \pm 1.3) \quad$ vs PCOS $(n=70, \quad \bar{x}=36.5 \pm 1.3)$ $(P=0.371)$. The proportion of Caucasians in the control group $(393 / 444,88.5 \%)$ was higher than in PCOS patients $(581 / 770,75.5 \%)(P<0.001)$. On the other hand, black women were more frequent in PCOS (105/770, 13.6\%) than in controls $(27 / 444,6.1 \%),(P<0.001)$. Furthermore, women of other races were more frequent in PCOS $(84 / 770$, $10.9 \%)$ than in controls $(24 / 444,5.4 \%),(P<0.001)$. In 26 (3.2\%) PCOS women the ethnicities were not recorded.

In non-PCOS women, blood pressures and anthropometric characteristics did not change in the different ethnicities. Regarding the association of the different ethnicities and PCOS features (Supplementary Table 1, see section on supplementary materials given at the end of this article), it was found that in PCOS the SBP was higher in Caucasians than in African descendants $(P<0.001)$. Diastolic blood pressures were higher in African descendant and other ethnicities women with PCOS than in Caucasians with PCOS, clearly in women's over 30 years of age $(P<0.001$ and $P=0.002$, respectively). These significances were observed only after the age of 25 years.

Regarding the biomarkers of adiposity, BW $(P<0.001)$, BMI $(P<0.001)$, WC $(P<0.001)$, WHR ratio $(P<0.001)$, $\mathrm{FM}(\%) \quad(P<0.001)$, and LAP $(P=0.039)$ were higher in African descendants PCOS than in Caucasians PCOS women; VAI was higher in other ethnicities than in Caucasians $(P<0.001)$ (Supplementary Table 1$)$. Among androgens, free testosterone showed to be higher in African descendants and other races women with PCOS when compared with Caucasians PCOS $(P<0.001$, and $P=0.005$, respectively). SHBG was lower in African descendants than in Caucasians PCOS $(P=0.003)$. 17-OHP4 concentrations was lower in African descendants than in Caucasians $(P=0.026)$ (Supplementary Table 2$)$.

In relation to the association of ethnicity and metabolic markers, fasting glucose was significantly lower in Caucasian PCOS women when compared with African descendants $(P<0.001)$ or other races $(P=0.022)$. In PCOS patients, insulin concentrations were higher in $\mathrm{AD}$ and women of other races than in Caucasians $(P<0.001$ and $P=0.008$, respectively) (Supplementary Table 3). The lower level of fasting glucose in Caucasians was maintained in all 5 years age strata (Supplementary Table 4). In PCOS,
African descendants presented higher levels of HbA1C when compared with Caucasians $(P=0.002)$ or other races $(P<0.001)$. HbA1C concentrations tended to be lower in Caucasians PCOS, particularly in women older than 25 years (Supplementary Table 4). HOMA-IR was also higher in African descendants $(P<0.001)$ and other races in PCOS women $(P=0.008)$ than in Caucasians. HDL-C was higher in Caucasians PCOS when compared with African descendants $(P<0.001)$ and other races $(P=0.001)$. The higher level of HDL-C in Caucasians PCOS was remarkable between the ages of 30 and 34 years (Supplementary Table 4).

Regarding menstrual patterns, in the control group all women presented normal menstrual cycles. Among PCOS women, 418/796 (52.5\%) had infrequent menses, 48/796 (6.0\%) presented frequent menses, 155/796 (19.5\%) had amenorrhea, and 175/796 (22.0\%) presented periods with normal intervals of 26-34 days. In the tendency analyses, the proportion of women with infrequent menses or amenorrhea increased over time $\left(x^{2}=11.3, P<0.001\right.$ and $x^{2}=5.8, P=0.015$, respectively). On the other hand, the proportions of women with either frequent periods or normal cycling periods remained stable with age $\left(x^{2}=2.1\right.$, $P=0.150$ and $x^{2}=0.3, P=0.555$, respectively).

The uterine volumes were $64.3 \pm 2.6 \mathrm{~cm}^{3}$ in nonPCOS normal cycling controls and $54.4 \pm 2.2 \mathrm{~cm}^{3}$ in PCOS patients $(P<0.001)$; the endometrium thicknesses in the control and PCOS groups were $6.3 \pm 1.7 \mathrm{~mm}$ and $6.4 \pm 0.3$ $\mathrm{mm}$, respectively $(P=0.033)$, and the ovarian volumes were $7.1 \pm 0.4 \mathrm{~cm}^{3}$ and $10.7 \pm 1.6 \mathrm{~cm}^{3}(P<0.001)$. Despite ovarian volume being larger in PCOS patients than in controls in each five-year range age group, from $\leq 19$ years to 39 years $(P<0.001$ for all strata comparisons), the tendency analyses showed that the ovarian volume presented a non-significant tendency to decline with advancing age either in controls $(\mathrm{F}=1.026, P=0.391)$ or in PCOS women $(\mathrm{F}=1.685, P=0.152)$. However, it is worth noting a non-significant decrease of $19 \%$ in the ovarian volume of controls with age (from $7.9 \mathrm{~cm}^{3}$ to $6.4 \mathrm{~cm}$ ).

Acne was present in $19 / 444(4.2 \%)$ controls, and in $153 / 796(19.2 \%)$ PCOS women $(P<0.001)$. Isolated hirsutism was found in $8 / 444(1.8 \%)$ controls and in $179 / 796(22.7 \%)$ PCOS women $(P<0.001)$. Hirsutism associated with acne was found in $2 / 444(0.4 \%)$ controls and in 194/796 (24.3\%) PCOS (P<0.001). Therefore, $375 / 796$ (47.1\%) PCOS patients presented clinical hirsutism. In addition, 268/796 (33.6\%) women with PCOS and 417/444 (93.9\%) controls did not present any sign of clinical hyperandrogenism $(P<0.001)$. In the tendency analyses, the proportion of PCOS patients 
with clinical signs of hyperandrogenism decreased over time $\left(x^{2}=6.1, P=0.013\right)$ at the expense of the significant decrease in acne with aging $\left(x^{2}=8.1, P=0.004\right)$, but the proportion of PCOS patients with isolated hirsutism or hirsutism associated with acne, remained stable $\left(x^{2}=1.7\right.$, $P=0.189$, and $x^{2}=1.9, P=0.161$, respectively). In controls, the proportion of patients with acne, hirsutism, and absence of any sign of clinical hyperandrogenism did not change over time.

Comparisons of blood pressure, anthropometric and anthropometric-metabolic characteristics between PCOS and control subjects, between $\leq 19$ years and 39 years of age are shown in Table 2. Both, SBP and DBP and all anthropometric parameters were significantly higher in PCOS women than in controls $(P<0.001$ for all comparisons). In Table 3 is shown that most of the biomarkers of carbohydrate metabolism were significantly higher in PCOS subjects than in non-PCOS controls $(P<0.001$ for all comparisons). Only G/I ratio was lower in PCOS subjects $(P<0.001)$. Regarding lipids, HDL-C was lower in PCOS but TC, LDL-C, and TG were higher in this subjects $(P<0.001$ for all comparisons). SHBG was lower in PCOS $(P<0.001)$ (Table 3$)$. These differences were also seen in all age strata after the twenties (Supplementary Table 5).

Body weight (BW), BMI, WC, WHR, FM(\%), VAI and LAP were significantly higher in PCOS women in all 5-year age strata (Supplementary Table 5). The tendency analyses of the SBP, DBP, and anthropometric variables over time in normal cycling women showed that only BMI had a statistically significant increase with age, even before their twenties $(\mathrm{F}=4.039, P=0.003)$. Oppositely, in PCOS subjects, BW, BMI, WC, WHR, and LAP showed significant tendency to increase in all 5-year age strata $(\mathrm{F}=9.516, P<0.001$, Fig. 1 and Supplementary Table 5).
Even though it is not shown in Fig. 1, VAI, and FM(\%) also showed a tendency to increase with age.

Carbohydrates, lipids, and androgens baseline characteristics of PCOS and non-PCOS women are compared in Table 3. The proportions of abnormal carbohydrate markers in PCOS and non-PCOS normal cycling controls were as follows: IFG in 86/753 (11.4\%) PCOS women and in $14 / 398(3.5 \%)$ controls $(P<0.001)$; glucose intolerance (IG) was present in 105/471 (22.3\%) PCOS women and in 18/227 (7.9\%) controls $(P<0.001)$; insulin resistance, using baseline insulin levels $\geq 84.7 \mathrm{pmol} / \mathrm{L}$, was found in $356 / 670$ (53.1\%) PCOS women and 47/305 (15.4\%) controls $(P<0.001)$. HOMA-IR score was $\geq 2.7$ in $113 / 647$ (17.41\%) PCOS women and $5 / 278(1.8 \%)$ controls $(P<0.001)$. T2DM was not found in controls but was diagnosed in 28/736 (3.8\%) PCOS women. In the tendency analyses, the proportion of PCOS women with IFG increased with age $\left(x^{2}=5.5, P=0.019\right)$ and the proportion of PCOS with IR also increased over time $(P=0.003)$. In addition, the proportion of PCOS women with HOMA-IR $\geq 2.7$ also increased $\left(x^{2}=11.5, P=(0.001)\right.$. The proportion of women with T2Dm was as follows: no case in the adolescent PCOS group, 3/158 (1.9\%) between 20 - 24 yo, 6/301 (2.0\%) between 25 - 29 yo, 13/207 (6.3\%) between $30-34$ yo, and 6/70 (8.5\%) $\geq 35$ years. In the tendency analysis the proportion of women with T2DM increased over time $\left(x^{2}=10.7, P=0.001\right)$.

At baseline, and in each of the 5-year strata, carbohydrate metabolic markers were compared in controls and PCOS (Fig. 2 and Supplementary Table 4). Only HOMA-S was higher in the control group when compared with PCOS subjects. All the other carbohydrate markers were higher in PCOS patients $(P<0.005$ for all comparisons). After the age of 25 years, in PCOS group, fasting glucose levels were higher when compared with

Table 2 Comparison of clinical and anthropometric characteristics between normal cycling non-PCOS women and women with PCOS.

\begin{tabular}{|c|c|c|c|}
\hline Variable ${ }^{a}$ & $n$ & Normal cycling non-PCOS $\bar{x} \pm$ s.D. & $\mathbf{N}$ \\
\hline SBP (mmHg) & 408 & $114 \pm 9$ & 737 \\
\hline $\mathrm{DBP}(\mathrm{mmHg})$ & 408 & $73 \pm 8$ & 738 \\
\hline BW (kg) & 421 & $65 \pm 10$ & 771 \\
\hline BMI $\left(\mathrm{kg} / \mathrm{m}^{2}\right)$ & 402 & $24.3 \pm 4.0$ & 719 \\
\hline WC (cm) & 399 & $72 \pm 8$ & 689 \\
\hline WHR ratio & 399 & $0.7 \pm 0.1$ & 688 \\
\hline FM (\%) & 378 & $30.5 \pm 6.3$ & 709 \\
\hline VAl & 376 & $1.0 \pm 0.1$ & 598 \\
\hline LAP (cm, mmol/L) & 357 & $14.5 \pm 2.6$ & 609 \\
\hline
\end{tabular}

\begin{tabular}{ccc}
\hline PCOS $\overline{\boldsymbol{x}} \pm$ s.D. & & $\boldsymbol{P b}^{\mathbf{b}}$ \\
\cline { 1 - 1 } $118 \pm 12$ & & $<0.001$ \\
$76 \pm 9$ & $<0.001$ \\
$74 \pm 16$ & $<0.001$ \\
$28.6 \pm 6.4$ & & $<0.001$ \\
$85 \pm 14$ & $<0.001$ \\
$0.8 \pm 0.1$ & $<0.001$ \\
$36.0 \pm 8.1$ & $<0.001$ \\
$2.2 \pm 1.8$ & $<0.001$ \\
$34.4 \pm 7.8$ & $<0.001$ \\
\hline
\end{tabular}

aSBP, systolic blood pressure; DBP, diastolic blood pressure; BW, body weight; BMI, body mass index; WC, waist circumference; WHR, waist-hip ratio; FM(\%), fat mass percentage; VAl, visceral adiposity index; LAP, lipid accumulation product; bStudent $t$ test.

https://ec.bioscientifica.com https://doi.org/10.1530/EC-19-0496 (c) 2020 The authors Published by Bioscientifica Ltd

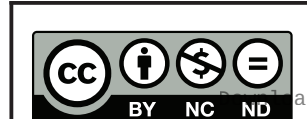

This work is licensed under a Creative Commons Attribution-NonCommercial-NoDerivatives 4.0 Internationab bicense.ifica . com at 04/26/2023 $09: 55: 10 \mathrm{AM}$ 
Table 3 Comparison of metabolic and androgen biomarkers between normal cycling non-PCOS women and women with PCOS.

\begin{tabular}{l} 
Variable \\
\hline Glucose $(\mathrm{nmol} / \mathrm{L})$ \\
Glucose $120(\mathrm{nmol} / \mathrm{L})$ \\
Insulin $(\mathrm{pmol} / \mathrm{L})$ \\
Insulin $120(\mathrm{pmol} / \mathrm{L})$ \\
G/I ratio \\
HOMA-IR \\
HOMA\%B \\
HbA1C $(\%)$ \\
TC (mmol/L) \\
TG (mmol/L) \\
HDL-C (mmol/L) \\
LDL-C (mmol/L) \\
Testosterone (nmol/L) \\
FT (pmol/cL) \\
SHBG (nmol/L) \\
FAI $(\%)$ \\
A4 $(\mathrm{nmol} / \mathrm{L})$ \\
DHEA $(\mathrm{nmol} / \mathrm{L})$ \\
DHEAS $(\mu \mathrm{ml} / \mathrm{L})$ \\
$17-O H P 4(\mathrm{nmol} / \mathrm{L})$
\end{tabular}

\begin{tabular}{|c|c|}
\hline$n$ & Normal cycling non-PCOS $\bar{x} \pm$ S.D. \\
\hline 395 & $4.7 \pm 0.4$ \\
\hline 224 & $5.3 \pm 0.1$ \\
\hline 303 & $45 \pm 4$ \\
\hline 217 & $329 \pm 59$ \\
\hline 396 & $12.6 \pm 1.7$ \\
\hline 397 & $0.9 \pm 0.1$ \\
\hline 397 & $102 \pm 3$ \\
\hline 350 & $5.0 \pm 0.4$ \\
\hline 379 & $4.4 \pm 0.8$ \\
\hline 379 & $0.9 \pm 0.1$ \\
\hline 378 & $1.4 \pm 0.3$ \\
\hline 377 & $2.5 \pm 0.7$ \\
\hline 373 & $0.9 \pm 0.8$ \\
\hline 358 & $2.6 \pm 1$ \\
\hline 357 & $55 \pm 1$ \\
\hline 348 & $1.8 \pm 0.2$ \\
\hline 354 & $4.7 \pm 1.7$ \\
\hline 302 & $14.1 \pm 1.9$ \\
\hline 360 & $3.7 \pm 0.2$ \\
\hline 356 & $2.6 \pm 0.2$ \\
\hline
\end{tabular}

\begin{tabular}{c}
\hline $\boldsymbol{n}$ \\
\hline 745 \\
465 \\
665 \\
446 \\
651 \\
644 \\
643 \\
604 \\
693 \\
690 \\
680 \\
681 \\
710 \\
686 \\
653 \\
634 \\
671 \\
553 \\
678 \\
687
\end{tabular}

\begin{tabular}{c}
\hline PCOS $\overline{\boldsymbol{x}} \pm$ s.o. \\
\hline $4.9 \pm 0.6$ \\
$6.4 \pm 0.1$ \\
$76 \pm 2$ \\
$612 \pm 115$ \\
$7.9 \pm 1.8$ \\
$1.5 \pm 0.1$ \\
$131 \pm 5$ \\
$5.5 \pm 0.1$ \\
$4.6 \pm 0.1$ \\
$1.2 \pm 0.1$ \\
$1.2 \pm 0.1$ \\
$1.2 \pm 0.3$ \\
$1.8 \pm 0.1$ \\
$4.5 \pm 2$ \\
$34 \pm 2$ \\
$5.7 \pm 0.9$ \\
$8.7 \pm 0.6$ \\
$17.6 \pm 1.4$ \\
$4.7 \pm 0.3$ \\
$3.6 \pm 0.3$
\end{tabular}

\begin{tabular}{c}
\hline \multicolumn{1}{c}{$\boldsymbol{p}^{\mathbf{b}}$} \\
\hline$<0.001$ \\
$<0.001$ \\
$<0.001$ \\
$<0.001$ \\
$<0.001$ \\
$<0.001$ \\
$<0.001$ \\
$<0.001$ \\
$<0.001$ \\
$<0.001$ \\
$<0.001$ \\
$<0.001$ \\
$<0.001$ \\
$<0.001$ \\
$<0.001$ \\
$<0.001$ \\
$<0.001$ \\
$<0.001$ \\
$<0.001$ \\
$<0.001$
\end{tabular}

aHOMA, homeostatic assessment model; G/I ratio, glucose/insulin ratio; HbA1C, glycated hemoglobin; TC, total cholesterol; TG, triglycerides; HDL-C, high density lipoprotein cholesterol; LDL-C, low density lipoprotein cholesterol; Testosterone, total testosterone; FT, free testosterone; SHBG, sex hormonebinding globulin; FAI, free androgen index; A4, androstenedione; DHEA, dehydroepiandrosterone; DHEAS, dehydroepiandrosterone sulfate; 17-OHP4, 17-hydroxyprogesterone; 'b ${ }^{b}$ tudent $t$ test.

controls $(P<0.001)$, and fasting insulin and insulin at 120 min concentrations, HOMA-IR, and HOMA\%B were higher in all age strata $(P<0.05$ for all comparisons). HOMA-S was higher among all 5-year range age strata of controls $(P<0.05$ for all comparisons). Regarding the tendency analyses, in PCOS patients, and after adjusting for BMI, fasting glucose $(\mathrm{F}=2.446, P=0.046)$, fasting insulin $(\mathrm{F}=2.883, P=0.022)$, and HOMA-IR $(\mathrm{F}=2.775, P=0.026)$ increased with advancing age (Fig. 2 ) but HOMA-S tended to decrease in all age strata (Supplementary Table 3). In controls, fasting glucose also tended to increase with advancing age ( $\mathrm{F}=2.636, P=0.034$; Fig. 2$)$.

Regarding lipids (Fig. 2 and Supplementary Table 4), TC, LDL-C, and TG were higher in PCOS women than in controls in all 5-year age strata. HDL-C levels were lower in PCOS women than in controls, but statistical significance was shown only in women older than 30 years of age. TC $(\mathrm{F}=6.499, P<0.001)$ and TG $(\mathrm{F}=4.034, P=0.003)$ tended to increase in PCOS women with aging (Fig. 2). In controls, only TC showed tendency to increase over time $(\mathrm{F}=2.446, P=0.046)$.

The comparisons of androgens between controls and PCOS patients (Table 3 ) showed that most androgens are higher and SHBG is lower in the PCOS group $(P<0.001$ in all comparisons). Fig. 3 and Supplementary Table 6 show the tendencies of the hormone concentrations between controls and PCOS women in each 5-year-range age. The baseline concentrations of testosterone, FT, A4, DHEAS, and 17-OHP4 were significantly higher in all age strata of PCOS women $(P<0.05$ for all comparisons). Sex-hormone-binding globulin (SHBG) was significantly lower in PCOS women in all age strata $(P<0.001$ for all comparisons $)$ and it tends to diminish over time without recalling statistical significance $(\mathrm{F}=2.379, P=0.051)$. Dehydroepiandrosterone (DHEA) levels were higher in PCOS women only in the range of 20-29 years of age.

In PCOS patients, testosterone $(\mathrm{F}=7.898, P<0.001)$, FAI $(\mathrm{F}=3.247, P=0.012)$, DHEA $(\mathrm{F}=5.741, \quad P<0.001)$, DHEAS $(\mathrm{F}=13.964, P<0.001), \mathrm{A} 4 \quad(\mathrm{~F}=4.008, P=0.013)$, and 17-OHP4 $(\mathrm{F}=2.752, P=0.027)$ showed statistically significant tendencies to decrease with aging progression (Fig. 3 and Supplementary Table 6). FT and cortisol also tended to decrease with age (data not shown). In the control group, also after adjusting for BMI (Fig. 3 and Supplementary Table 6), testosterone showed a statistically significant tendency to decrease from 20 years to 39 years of age $(\mathrm{F}=2.587, P=0.037)$ meanwhile FAI $(\mathrm{F}=2.975$, $P=0.020), \mathrm{A} 4(\mathrm{~F}=3.626, P=0.007)$, and DHEAS $(\mathrm{F}=2.630$, $P=0.034)$ tended to decrease only after 30 years of age. Cortisol also decreased with advancing age $(\mathrm{F}=4.051$, $P=0.001$ ) but SHBG, and DHEA did not show any trends to decrease in the normal cycling women during their reproductive years (Supplementary Table 6). 

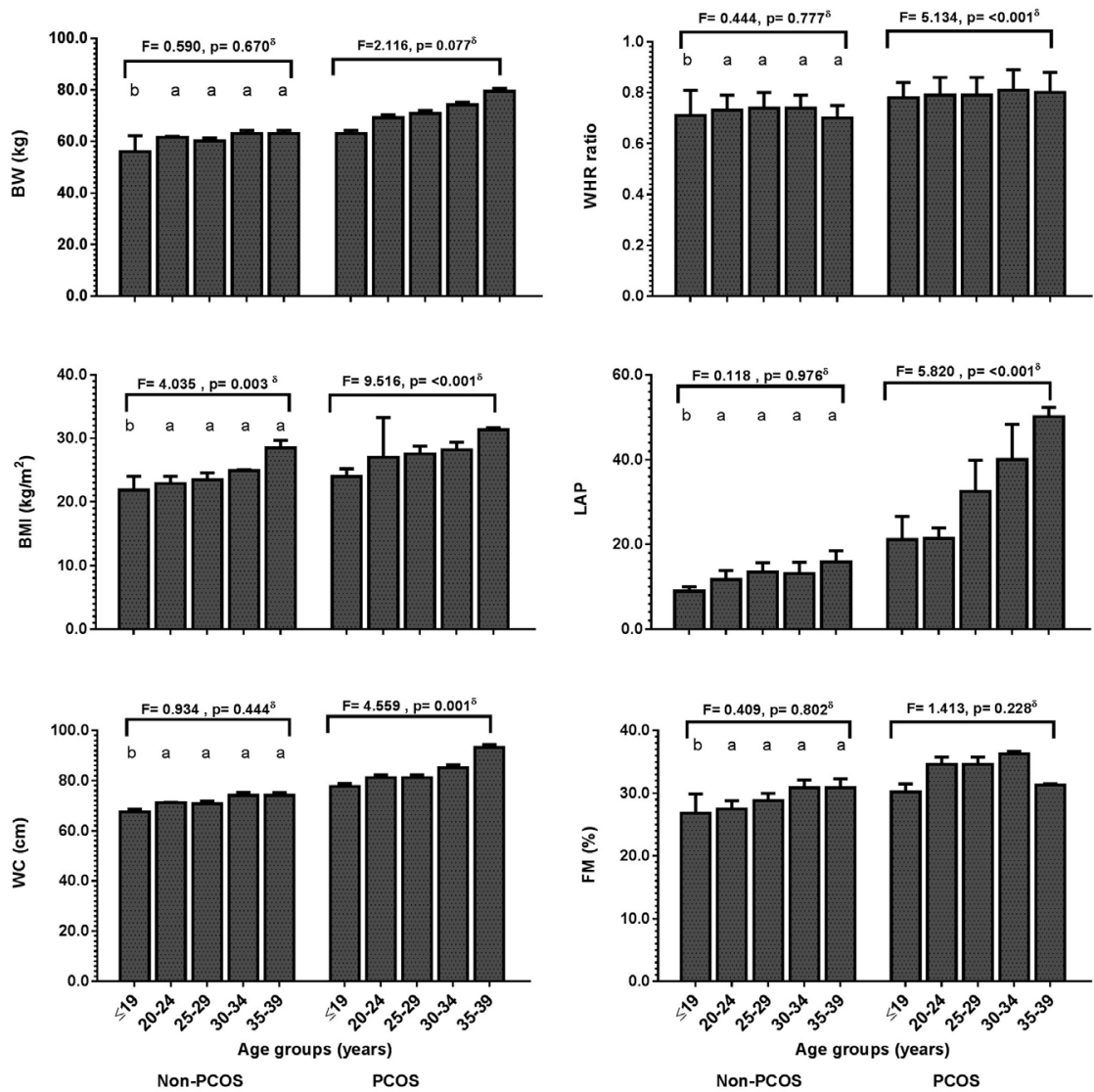

\begin{abstract}
Figure 1
Comparison of the modifications in the anthropometric parameters between normal cycling women and PCOS patients with advancing age. Results are given in $\bar{x} \pm$ s.D. ${ }^{\delta}$ Trend analysis, from $\leq 19$ years to 39 years in controls and in PCOS women using Ancova with Bonferroni post hoc test. $a=P<0.001$, for controls and PCOS within group comparison. $\mathrm{b}=P<0.05$, for controls and PCOS within group comparison.
\end{abstract}

* trend analysis, from $\leq 19$ to 39 years old $a=p<0.001$, for controls and PCOS within group comparison $b=p<0.05$, for controls and PCOS within group comparison

\section{Discussion}

The current study investigated possible changes in the clinical and biochemical characteristics of PCOS women over time. With this purpose, the study included a representative number of patients with PCOS up to the age of 40 and compared them with normal cycling women without PCOS. In short, the results reported here showed that (a) the impact of ethnicities on PCOS characteristics both at baseline and along the advancing age are still unclear but adiposity markers abnormalities are more severe in African descendants; (b) the menstrual intervals did not improve over time; instead, infrequent menses and amenorrhea tended to increase with age, at least until the age of 39 years; (c) blood pressures were higher in PCOS, but remained stable with advancing age; (d) most of the anthropometric parameters tended to increase in PCOS subjects in all 5-year age strata; (e) the carbohydrate metabolism markers, and TC tended to increase with advancing age in PCOS; in controls, only TC tended to significantly increase over time; (f) both ovarian and adrenal androgens tended to decrease over time in both PCOS and control groups; however, in PCOS subjects, androgen concentrations remained higher in all age-strata when compared with controls. Even only women under 40 were included in the current study, it is possible that in older women some differences may be even more evident.

The proportion of non-Caucasian women was higher in the PCOS group, but little is known about the influence of race on the prevalence or characteristics of PCOS (1). In the present study abnormal fat distribution, and fat percentage, and biomarkers of dysglycemia and dyslipidemia were more remarkable in African descendants PCOS. From the metabolic perspective, but not included in the present study, Japanese women with PCOS seem less obese and Indian women seem to present higher insulin resistance $(44,45)$. Metabolic syndrome in PCOS women seems to be more prevalent in black patients (46); however, this comparison was not performed in our study. https://ec.bioscientifica.com https://doi.org/10.1530/EC-19-0496 (c) 2020 The authors Published by Bioscientifica Ltd
This work is licensed under a Creative Commons Attribution-NonCommercial-NoDerivatives 4.0 Internationab sicense.ifica . com at 04/26/2023 09:55:10AM 

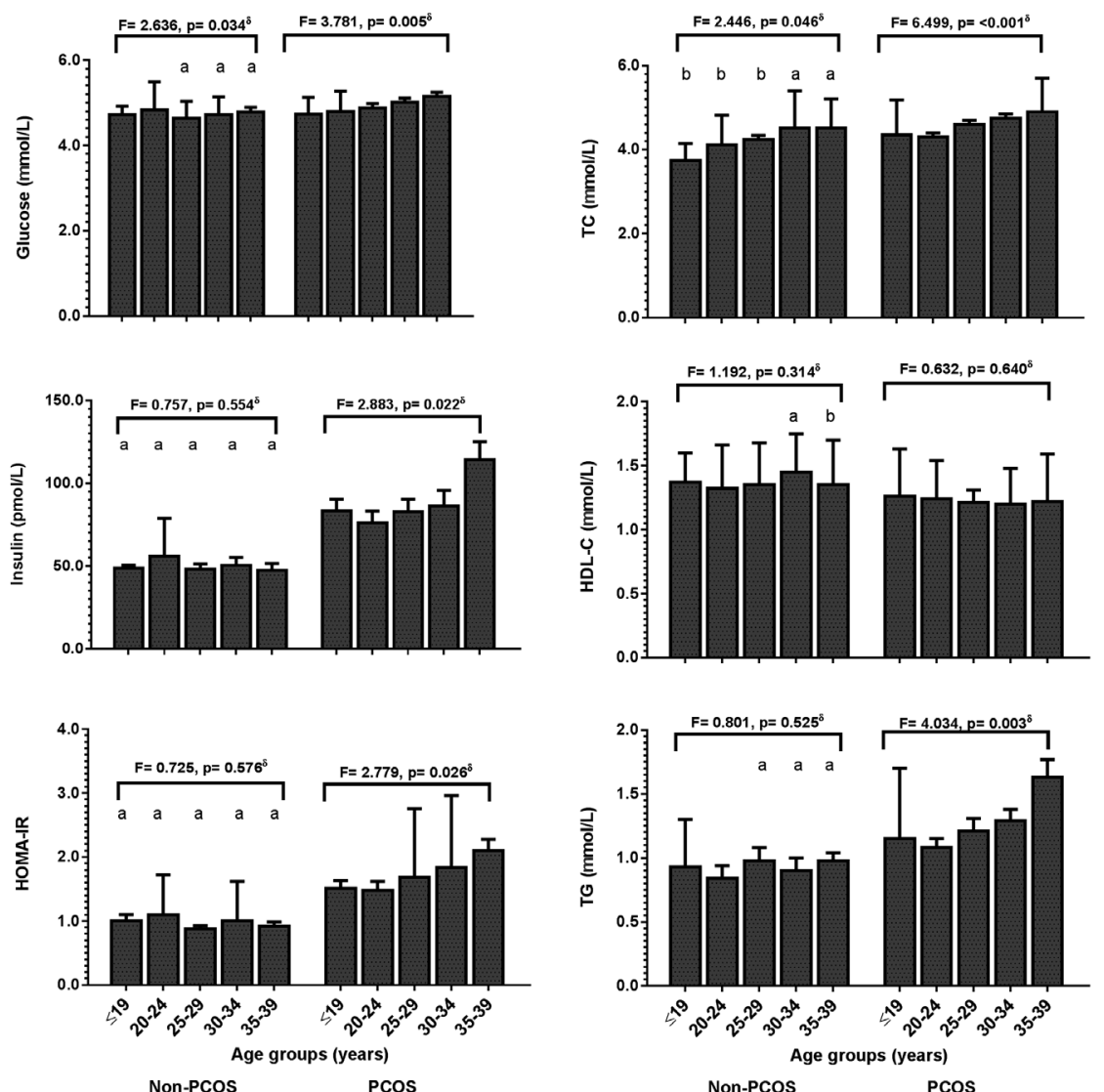

\begin{abstract}
Figure 2
Comparison of the modifications in the carbohydrate and lipid markers between normal cycling women and women with PCOS with advancing age. Results are given in $\bar{x} \pm$ S.D. ${ }^{\delta}$ Trend analysis, from $\leq 19$ years to 39 years of aging in controls and in PCOS women using Ancova with Bonferroni post hoc test. $a=P<0.001$, for controls and $\mathrm{PCOS}$ within group comparison. $\mathrm{b}=P<0.05$, for controls and PCOS within group comparison.
\end{abstract}

Results are given in $\bar{x} \pm$ SD

* trend analysis, from $\leq 19$ to 39 years old $a=p<0.001$, for controls and PCOS within group comparison $b=p<0.05$, for controls and PCOS within group comparison

In concordance with results found in the current study, DHEAS tend to be higher in Caucasian women with PCOS than in black women $(47,48,49)$. On the other hand, free testosterone levels were higher in African descendant PCOS than in Caucasians PCOS. Taking in account these findings, appropriate ethnic guidelines have been suggested for better screening and characterization of PCOS in different populations $(50,51)$.

Regarding the menstrual cycle length, a number of cross-sectional $(6,13,19)$ and a few longitudinal studies $(4,17)$ have reported that menstrual cycles become more regular in PCOS aging women and this normalization has been attributed to a decline in the number of ovarian follicles and to an increased number of ovulatory cycles with aging $(4,18)$. The prevalence of infrequent periods and amenorrhea, surrogates for oligo and anovulation, in more than $70 \%$ of PCOS patients seen in the current study is in accordance with previous reports $(10,17,19$, 46). However, in the current study both amenorrhea and infrequent menses increased over time and the women with normal menstrual cycling periods remained stable. The increase in the number of PCOS patients with infrequent menses or amenorrhea over time when free of previous treatment seems to be new and indicates a possible worsening of this a condition when patients had not been submitted to any treatment before analysis.

Moreover, the increase of infrequent periods and amenorrhea with age found in the current study indicate that this criterion persists useful for making the diagnosis of PCOS until the end of the fourth decade. Non-significant decrease in amenorrhea or no changes in infrequent menses were described by others $(17,19)$. It is worth noting that many studies on this subject did not report in detail the menstrual cycle pattern $(10,13,17,52)$. Contrary to others $(13,17,52)$, in the current study the number of PCOS patients with regular cycles remained stable with age and the number of menstrual cycles per year was also reported to be stable in PCOS (10). The inconsistencies among studies may be due to the population characteristics, study design, 

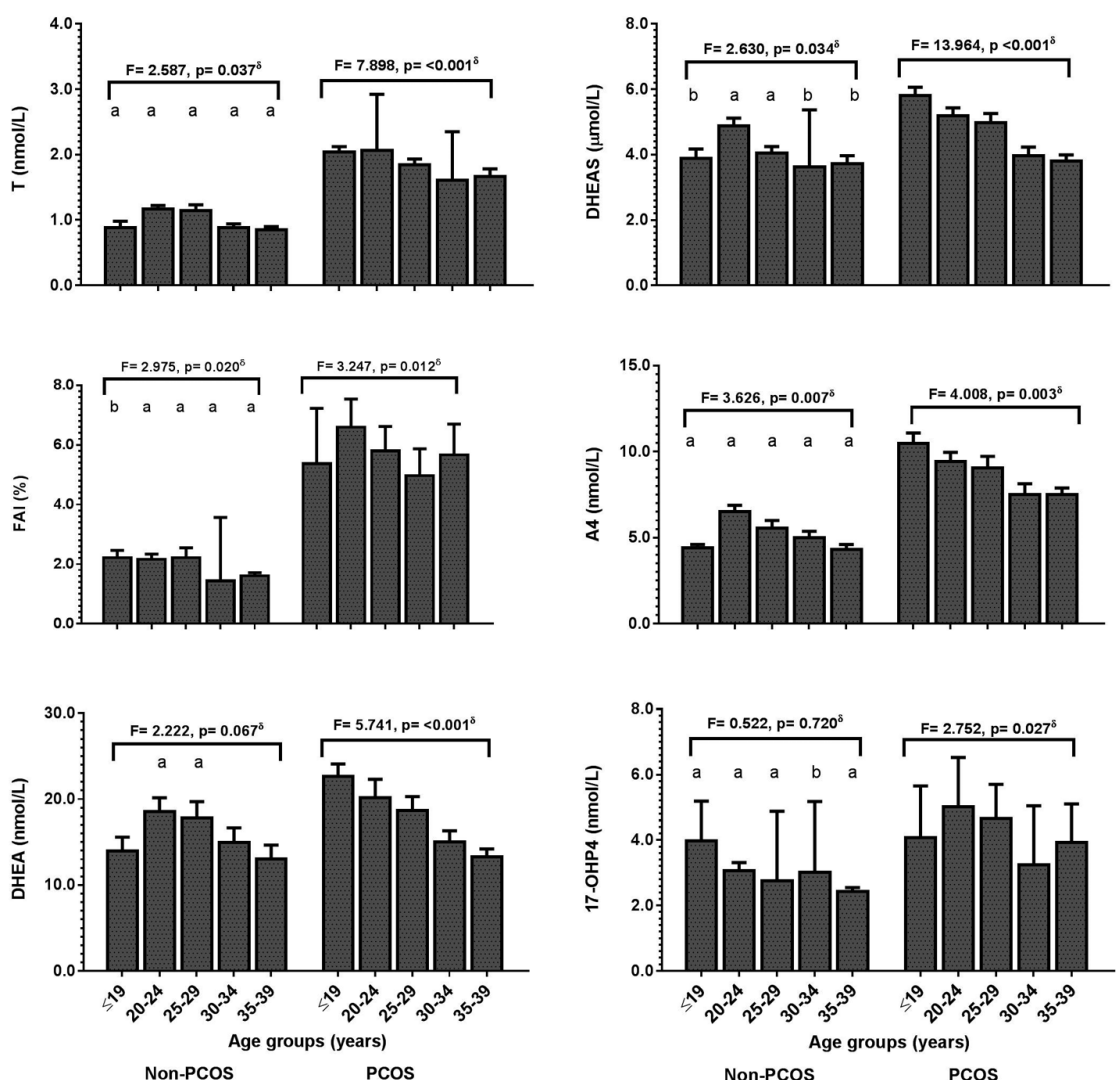

\begin{abstract}
Figure 3
Comparison of the modifications in the androgen markers between normal cycling women and women with PCOS with advancing age. Results are given in $\bar{x} \pm$ s.D. ${ }^{\top}$ Trend analysis, from $\leq 19$ years to 39 years of aging in controls and in PCOS women using Ancova with Bonferroni post hoc test. $a=P<0.001$, for controls and PCOS within group comparison. $\mathrm{b}=P<0.05$, for controls and PCOS within group comparison.
\end{abstract}

\section{Results are given in $\overline{\mathbf{x}} \pm \mathrm{SD}$ \\ * trend analysis, from $\leq 19$ to 39 years old $a=p<0.001$, for controls and PCOS within group comparison $b=p<0.05$, for controls and PCOS within group comparison}

diagnostic criteria, or to previous interventions. In addition, most changes observed in the menstrual pattern and ovary volume over time have been found only in women over 35 years. Due to the low power of the available studies, more investigation is needed, mainly including a higher number of individuals over 30 years of age.

The present study confirmed that the ovaries of PCOS women are bigger compared to the ovaries of non-PCOS normal cycling women $(10,15)$. After stratification into the 5 -year range age strata, from $\leq 19$ years to 39 years of age, the current study could not show any significant decline in ovary volume over time, neither in PCOS patients nor in the control women. Favorably with this outcome similar observations were also previously reported (10, $18,19)$. Two studies have reported that in PCOS the ovarian volume remains stable until the age of 35 years and present a minor decline afterwards $(53,54,55,56)$. The lack of significance in the ovarian volume decreases with age also suggests that this remains reliable to make PCOS diagnoses during the aging process. The finding of stable ovarian volume with age have been attributed to a slower depletion of ovarian reserve in PCOS $(16,19$, $55)$. On the other hand, others have reported a decrease in ovarian volume over time in both healthy individuals $(10,55,56)$ and in women with PCOS, markedly after the age of 37 years $(4,12)$. Even in those studies that have reported a decrease in ovarian volume, the decreases were not remarkable and occurred only in the end of the fourth decade. Anyway, these possible discrepancies among studies are not clear at this time, but they have been attributed to inter-rater variability and the use of different machines to measure the ovaries.

The prevalence of the four PCOS phenotypical groups (A, B, C, D) was consistent with studies performed in other populations $(57,58,59,60)$. Similar blood pressures and anthropometric parameters in the four phenotypes found in the current study are in concordance with previous reports $(60,61)$. Higher levels of testosterone, A4, DHEAS, and FAI in PCOS patients with phenotypes $A$ and $C$ were expected and equally found in other study (60). To dissect the clinical and laboratorial characteristics 
of each phenotypes by age-strata over time was not an objective of the current study.

In PCOS women as a whole group acne tended to decrease with age, but hirsutism remained stable in all age strata. As far as we know, there is only one longitudinal report that have shown a decrease in the intensity of both acne and hirsutism with aging in PCOS women (20). Recently, acne and hirsutism were reported to suffer a small decrease with aging statistical significance (10). Women without any clinical sign of hyperandrogenism decreased with age in PCOS, perhaps due to the decline of androgen levels over time. The definition of hirsutism by the presence or absence of thick hair in the upper lip, chin, chest, upper or lower back, upper or lower abdomen, upper arms and thighs during the clinician evaluation (or by the patient complaint) was used in the present study to avoid inconsistent results due to ethnicity and interrate variability when the Ferriman-Gallwey score is used. In addition, the patient complaint has relevance in the treatment and well-being of patients.

All anthropometric parameters showed a tendency toward worsening with the advancing age in PCOS women. In normal controls, a minor increase in BW, BMI, WC, and FM was already reported (51). In PCOS women older than 30 years, but not before this age, higher BMI, WC, and WHR values have also been shown $(10,17,18$, 62 ). The demonstration of a major increase in LAP in PCOS women during the reproductive years was consistent with the findings of another recent publication (62). It is thought that the worsening of anthropometric measures in PCOS with age may reflect a complex relationship between androgen carbohydrate, and lipid abnormalities in PCOS subjects.

In PCOS women, metabolic abnormalities generally display an early start and worsening in conjunction with the existence of hyperandrogenemia (63). Higher fasting glucose levels, in PCOS women compared with controls, within each age strata seen in the present study corroborates previous publications (10), but glucose was reported to be negatively correlated with age in another report (24). A few observational studies have shown that PCOS women present impaired glucose tolerance after 30 years of age $(10,18,62)$ and the increase in fasting glucose levels over time in PCOS have been attributed to a derangement in insulin sensitivity (17).

Fasting insulin did not tend to increase in the controls in the current study at all ages. Otherwise, insulin levels gradually increased in PCOS subjects beginning as early as $\leq 19$ years of age. The tendency of increasing insulin levels over time seen in the present study has rarely been shown.
A number of reports have shown however, that at baseline insulin levels are higher in PCOS women, mainly after 25 to 30 years of age $(18,60)$. On the other hand, other studies have denied that insulin increases in PCOS over time $(4,6,13,19,21,23,62,64,65)$, particularly in those patients in whom BMI, WC, and WHR remained stable. The baseline concentration of fasting insulin was in fact reported to decrease $(17)$ or remain stable $(4,15)$ during the aging process. It is possible that a decrease in androgens (65) and an increase in fat distribution abnormalities influences insulin levels over time; additionally, different populations, or different study eligibility might explain possible inconsistencies across studies.

After correcting for BMI, the current results show that the IR increased with aging in the PCOS group between 20 and 39 years of age. HOMA-IR score was reported to be higher in PCOS women than in controls only in women older than 30 years $(18,24,52)$. It is possible that IR worsens as a result of the accumulation of abdominal fat $(18,24)$. Contrary to this a longitudinal study, including PCOS women, evaluated in two different occasions, no more than seven years apart, reported a decline of HOMA-IR score (31). Furthermore, another publication showed that the differences in this metabolic marker between normal controls and PCOS women become less evident over time (16). All in all, it can be assumed that IR worsens in PCOS patients during the reproductive years and this worsening seems to be a result of increasing abdominal obesity (18). Different from the findings of the present study, minor IR was reported in healthy women with aging $(18,52)$.

A statistically significant decrease in androgen levels with aging was well-documented in the current study, in both control and PCOS groups. Though testosterone levels are higher in PCOS women, the decrease in their concentrations with aging was greater in controls. In PCOS women, testosterone decreased in $20 \%$, from 20 to 24 year strata, what is not different from the decrease of $25 \%$ reported in a longitudinal study including women between 22 years and 43 years of age (5). In general, without normalization, a decline in testosterone levels in PCOS patients ranging from 20 and $50 \%$ have been reported, markedly after 30 years of age $(3,5,6,8,16,18$, $19,21,24,66,67,68)$. This fact shows that the biochemical hyperandrogenism, as a parameter to diagnose PCOS, becomes weak with age and may hamper the diagnosis of PCOS after 30 years of age. Despite these findings, two prospective studies did not show significant changes in testosterone levels in PCOS women with advancing age $(67,69)$. In addition, a small number of cross-sectional studies also did not report any decrease in testosterone 
levels in PCOS women either younger or older than 30 years $(70,71)$. These inconsistent results may be explained by different criteria used to diagnose PCOS, study size, previous treatment, and/or ethnic characteristics of the population included. Despite controversies, most data support the knowledge that as women grow older, there is a significant decrease in androgen production, but not as much as in non-PCOS women. The mechanisms are largely attributed to a decreased theca cell number and function in PCOS over time $(72,73,74)$. The concentrations of SHBG have been described either to increase (15) or stabilize in PCOS.

A significant decrease in DHEA with aging in normal ovulatory women was reported (71), but in the current study, despite showing a decrease of $30 \%$, statistical significance was not reached in non-PCOS subjects up to 39 years of age. However, similar to the current study, the DHEA levels were reported by others to decline in PCOS women with the aging process $(3,19)$. The decrease in DHEA with aging is attributed to alterations in the sensitivity or responsivity of the adrenal to the adrencorticotropic hormone (ACTH) stimulation with a diminished adrenocortical production rate with age $(6$, $49,72,73$ ) and a decrease in the zone reticular mass (73). A decrease in the pulse secretion of DHEA with age was also observed but no neuroendocrine contribution was reported (75). In normal cycling women older than 20 years, the decrease in DHEAS of about $24 \%$, observed in the current study in controls, is in accordance with other studies that have also reported reduction in DHEAS after the 20 s in normal ovulatory women $(10,17,18,19,24,49$, $70,71,75,76)$. A decline of 18 to $36 \%$ in DHEAS in PCOS women, between the ages of 20 years and 45 years, have been reported $(4,5,77)$, giving support to the findings of the current study. The mechanisms involved in the adrenal androgen decline with aging are unclear, but it seems to be related to a diminished adrenal stimulation over time or to a diminished activity of certain steroidogenic enzymes $(5,71,78)$.

Finally, certain limitations of this study must be considered. The cross-sectional design is limited to reveal possible associations in a determined moment and does not disclose a cause-effect relationship. However, longitudinal studies designed to verify modifications in the characteristic of PCOS women are not free of bias and the changes in the life style and previous therapeutic interventions between visits are the main drawbacks. Furthermore, the few longitudinal studies currently available $(4,17,31,56,79)$ have shown results comparable to those of cross-sectional designs. The final methods used to quantify androgens in the present study are not the current gold standards, but the immunoassays used were adequate for use during the period of sample collection. In addition, all imprecisions of these methods were given in a detailed manner. Moreover, a control group was included for comparisons using the same assays and the endpoints were differences or changes in hormone analysis other than the absolute values. Despite these limitations, the main objective of the present study was fulfilled. The study included a large number of patients carefully diagnosed with PCOS using recommended methods and included non-PCOS normal cycling women from the same age ranges. Finally, all variables were analyzed after the correction for BMI. The inclusion of patients with ages ranging from $\leq 19$ years to 39 years provided information for this wide age period and for each of the 5-year age strata.

\section{Conclusions}

The present study strengthens and extends the current knowledge by showing that the advancing age influence many characteristics of PCOS women, including those used in the current systems to define the syndrome, particularly the androgen concentrations. Ovarian volumes seem to be more stable, at least until the age of 39 years. Blood pressures are higher in PCOS than in non-PCOS women, being striking in African descendant PCOS. Biomarkers of adiposity amount and distribution change over time and also are more severe in non-Caucasian PCOS subjects. Fasting glucose levels were lower in Caucasian PCOS but tended to be higher in PCOS women over 25 years of age. Fasting insulin levels are higher in African descendant PCOS and tended to be higher than in non-PCOS over time. The androgen levels fall with age but remain elevated. As the androgen status criterion may affect the prevalence of PCOS when the syndrome is diagnosed at different periods of reproductive years, it is recommended that an age-specific androgen cut-off is considered, at least for diagnosis of biochemical hyperandrogenism in women with PCOS, aged from $\leq 19$ years to 39 years. Future controlled studies including PCOS women at all ages, even after menopause, free of any type of previous treatment would give opportunity for tailoring more precise diagnosis and better preventive care.
This work is licensed under a Creative Commons Attribution-NonCommercial-NoDerivatives 4.0 enternationad ticense ifica.com at 04/26/2023 09:55:10AM 


\section{Supplementary materials}

This is linked to the online version of the paper at https://doi.org/10.1530/ EC-19-0496.

\section{Declaration of interest}

The authors declare that there is no conflict of interest that could be perceived as prejudicing the impartiality of the research reported.

\section{Funding}

This research did not receive any specific grant from any funding agency in the public, commercial or not-for-profit sector.

\section{Author contribution statement}

S F M: design, data's description, statistical analysis, and writing the manuscript. M M W Y: data search, revision of the manuscript. M A S M: data search, revision of the manuscript. B B B: data search, data analysis, revision of the manuscript. J M S J: data search, revision of the manuscript. E C B: data search, revision of the manuscript.

\section{Acknowledgments}

The authors appreciate all criticisms and the English reviews of the manuscript.

\section{References}

1 Skiba MA, Islam RM, Bell RJ \& Davis SR. Understanding variation in prevalence estimates of polycystic ovary syndrome: a systematic review and meta-analysis. Human Reproduction Update 201824 694-709. (https://doi.org/10.1093/humupd/dmy022)

2 Lauritsen MP, Bentzen JG, Pinborg A, Loft A, Forman JL, Thuesen LL, Cohen A, Hougaard DM \& Nyboe Andersen A. The prevalence of polycystic ovary syndrome in a normal population according to the Rotterdam criteria versus revised criteria including anti-Mullerian hormone. Human Reproduction 201429 791-801. (https://doi. org/10.1093/humrep/det469)

3 Kushnir VA, Halevy N, Barad DH, Albertini DF \& Gleicher N. Relative importance of $\mathrm{AMH}$ and androgens changes with aging among nonobese women with polycystic ovary syndrome. Journal of Ovarian Research 20158 45. (https://doi.org/10.1186/s13048-015-0175-x)

4 Carmina E, Campagna AM \& Lobo RA. A 20-year follow-up of young women with polycystic ovary syndrome. Obstetrics and Gynecology 2012119 263-269. (https://doi.org/10.1097/ AOG.0b013e31823f7135)

5 Davison SL, Bell R, Donath S, Montalto JG \& Davis SR. Androgen levels in adult females: changes with age, menopause, and oophorectomy. Journal of Clinical Endocrinology and Metabolism 2005 90 3847-3853. (https://doi.org/10.1210/jc.2005-0212)

6 Winters SJ, Talbott E, Guzick DS, Zborowski J \& McHugh KP. Serum testosterone levels decrease in middle age in women with the polycystic ovary syndrome. Fertility and Sterility 200073 724-729. (https://doi.org/10.1016/s0015-0282(99)00641-x)

7 Mortensen M, Ehrmann DA, Littlejohn E \& Rosenfield RL. Asymptomatic volunteers with a polycystic ovary are a functionally distinct but heterogeneous population. Journal of Clinical Endocrinology and Metabolism 200994 1579-1586. (https://doi. org/10.1210/jc.2008-2771)

8 Amirikia H, Savoy-Moore RT, Sundareson AS \& Moghissi KS. The effects of long-term androgen treatment on the ovary. Fertility and Sterility 198645 202-208. (https://doi.org/10.1016/s00150282(16)49155-7)
9 Neoklis AG, Anastasia KA, Damianaki K, Nikolaos DR, Markantes G Papadopoulos V, Adonakis GL, Decavalas G \& Panidis D. Polycystic ovary syndrome morphology is associated with hyperandrogenemia and insulin resistance in women with polycystic ovary syndrome (PCOS). Journal of Steroids and Hormonal Science 20167 1-5. (https:// doi.org/10.4172/2157-7536.1000169)

10 Liang SJ, Hsu CS, Tzeng CR, Chen CH \& Hsu MI. Clinical and biochemical presentation of polycystic ovary syndrome in women between the ages of 20 and 40. Human Reproduction 201126 3443-3449. (https://doi.org/10.1093/humrep/der302)

11 Fauser BC, Tarlatzis BC, Rebar RW, Legro RS, Balen AH, Lobo R, Carmina E, Chang J, Yildiz BO, Laven JS, et al. Consensus on women's health aspects of polycystic ovary syndrome (PCOS): the Amsterdam ESHRE/ASRM-Sponsored 3rd PCOS Consensus Workshop Group. Fertility and Sterility 201297 28.e25-38.e25. (https://doi. org/10.1016/j.fertnstert.2011.09.024)

12 Usmani A, Rehman R \& Qamar A. Effect of age on uterine and ovarian morphology with polycystic ovaries. Journal of the Pakistan Medical Association 201464 1119-1122.

13 Elting MW, Korsen TJ, Rekers-Mombarg LT \& Schoemaker J. Women with polycystic ovary syndrome gain regular menstrual cycles when aging. Human Reproduction 200015 24-28. (https://doi.org/10.1093/ humrep/15.1.24)

14 Alsamarai S, Adams JM, Murphy MK, Post MD, Hayden DL, Hall JE \& Welt CK. Criteria for polycystic ovarian morphology in polycystic ovary syndrome as a function of age. Journal of Clinical Endocrinology and Metabolism 200994 4961-4970. (https://doi.org/10.1210/ jc.2009-0839)

15 Teede HJ, Misso ML, Costello MF, Dokras A, Laven J, Moran L, Piltonen T, Norman RJ \& International PCOS Network. Recommendations from the international evidence-based guideline for the assessment and management of polycystic ovary syndrome. Fertility and Sterility $2018110364-379$. (https://doi.org/10.1016/j. fertnstert.2018.05.004)

16 Tehrani FR, Solaymani-Dodaran M, Hedayati M \& Azizi F. Is polycystic ovary syndrome an exception for reproductive aging? Human Reproduction 201025 1775-1781. (https://doi.org/10.1093/ humrep/deq088)

17 Brown ZA, Louwers YV, Fong SL, Valkenburg O, Birnie E, de Jong FH, Fauser BC \& Laven JS. The phenotype of polycystic ovary syndrome ameliorates with aging. Fertility and Sterility 201196 1259-1265. (https://doi.org/10.1016/j.fertnstert.2011.09.002)

18 Panidis D, Tziomalos K, Misichronis G, Papadakis E, Betsas G, Katsikis I \& Macute D. Insulin resistance and endocrine characteristics of different phenotypes of polycystic ovary syndrome: a prospective study. Human Reproduction 201227 541-549. (https:// doi.org/10.1093/humrep/der418)

19 Bili H, Laven J, Imani B, Eijkemans MJ \& Fauser BC. Age-related differences in features associated with polycystic ovary syndrome in normogonadotrophic oligo-amenorrhoeic infertile women of reproductive years. European Journal of Endocrinology 2001145 749-755. (https://doi.org/10.1530/eje.0.1450749)

20 Lauritsen MP, Loft A, Pinborg A, la Cour Freiesleben N, Cohen A, Petersen JH, Mikkelsen AL, Bjerge MR \& Nyboe Andersen A Individualised gonadotrophin ovulation induction in women with normogonadotrophic anovulatory infertility: a prospective, observational study. European Journal of Obstetrics, Gynecology, and Reproductive Biology 2017210 76-82. (https://doi.org/10.1016/j. ejogrb.2016.12.010)

21 Welt CK \& Carmina E. Lifecycle of polycystic ovary syndrome (PCOS): from in ultero to menopause. Journal of Clinical Endocrinology and Metabolism 201398 4629-4638. (https://doi.org/10.1210/ jc.2013-2375)

22 Pasquali R \& Gambineri A. Polycystic ovary syndrome: a multifaceted disease from adolescence to adult age. Annals of the New York Academy of Sciences 20061092 158-174. (https://doi.org/10.1196/ annals.1365.014) 
23 Schmidt J, Brännström M, Landin-Wilhelmsen K \& Dahlgren E. Reproductive hormone levels and anthropometry in postmenopausal women with polycystic ovary syndrome (PCOS): a 21-year follow-up study of women diagnosed with PCOS around 50 years ago and their age-matched controls. Journal of Clinical Endocrinology and Metabolism 201196 2178-2185. (https://doi.org/10.1210/jc.2010-2959)

24 Livadas S, Kollias A, Panidis D \& Diamanti-Kandarakis E. Diverse impacts of aging on insulin resistance in lean and obese women with polycystic ovary syndrome: evidence from 1345 women with the syndrome. European Journal of Endocrinology 2014171 301-309. (https://doi.org/10.1530/EJE-13-1007)

25 Bentzen JG, Forman JL, Johannsen TH, Pinborg A, Larsen EC \& Nyboe Andersen A. Ovarian adrenal follicle subclasses and antiMullerian hormone during normal reproductive aging. Journal of Clinical Endocrinology and Metabolism 201398 1602-1611. (https:// doi.org/10.1210/jc.2012-1829)

26 New MI, Lorenzen F, Lerner AJ, Kohn B, Oberfield SE, Pollack MS, Dupont B, Stoner E, Levy DJ, Pang S, et al. Genotyping steroid 21-hydroxylase deficiency: hormonal reference data. Journal of Clinical Endocrinology and Metabolism 198357 320-326. (https://doi. org/10.1210/jcem-57-2-320)

27 de Medeiros SF, Ormond CM, de Medeiros MAS, Santos NS, Banhara CR \& Yamamoto MMW. Metabolic and endocrine connections of 17-hydroxypregnenolone in polycystic ovary syndrome women. Endocrine Connections 20176 479-488. (https:// doi.org/10.1530/EC-17-0151)

28 Baloch Z, Carayon P, Conte-Devolx B, Demers LM, FeldtRasmussen U, Henry JF, LiVosli VA, Niccoli-Sire P, John R, Ruf J, et al. Laboratory medicine practice guidelines. Laboratory support for the diagnosis and monitoring of thyroid disease. Thyroid 200313 3-126 (https://doi.org/10.1089/105072503321086962)

29 de Medeiros SF, Yamamoto MMW, de Medeiros MAS, Barbosa JS \& Norman RJ. Should subclinical hypothyroidism be and exclusion criterion for the diagnosis of polycystic ovary syndrome? Journal of Reproduction and Infertility 201618 242-250.

30 de Medeiros SF, Yamamoto MMW, Bueno HB, Belizário D \& Barbosa JS. Prevalence of elevated glycated hemoglobin concentrations in the polycystic ovary syndrome: anthropometrical and metabolic relationship in Amazonian women. Journal of Clinical Medicine Research 20146 278-286. (https://doi.org/10.14740/ jocmr1829w)

31 Carmina E, Oberfield SE \& Lobo RA. The diagnosis of polycystic ovary syndrome in adolescents. American Journal of Obstetrics and Gynecology 2010203 201.e1-201.e5. (https://doi.org/10.1016/j. ajog.2010.03.008)

32 Fraser IS, Critchley HO, Broder M \& Munro MG. The FIGO recommendations on terminologies and definitions for normal and abnormal uterine bleeding. Seminars in Reproductive Medicine 201129 383-390. (https://doi.org/10.1055/s-0031-1287662)

33 Rosenfield RL \& Ehrmann DA. The pathogenesis of polycystic ovary syndrome (PCOS): the hypothesis of PCOS as functional ovarian hyperandrogenism revisited. Endocrine Reviews 201637 467-520. (https://doi.org/10.1210/er.2015-1104)

34 McAuley KA, Williams SM, Mann JI, Walker RJ, Lewis-Barned NJ Temple LA \& Duncan AW. Diagnosing insulin resitance in the general population. Diabetes Care 200124 460-464. (https://doi. $\operatorname{org} / 10.2337 /$ diacare.24.3.460)

35 Geloneze B, Vasques AC, Stabe CF, Pareja JC, Rosado LE, Queiroz EC, Tambascia MA \& BRASMS Investigators. HOMA1-IR and HOMA2-IR indexes in identifying insulin resistance and metabolic syndrome: Brazilian Matabolic Syndrome Sudy (BRAMS). Arquivos Brasileiros de Endocrinologia e Metabologia 200953 281-287. (https://doi. org/10.1590/s0004-27302009000200020)

36 Wild RA, Vesely S, Beebe L, Whitsett T \& Owen W. Ferriman Gallwey self-scoring I: performance assessment in women with polycystic ovary syndrome. Journal of Clinical Endocrinology and Metabolism 2005 90 4112-4114. (https://doi.org/10.1210/jc.2004-2243)
37 Balen AH, Laven JS, Tan SL \& Dawailly D. Ultrasound assessment of the polycystic ovary: international consensus definitions. Human Reproduction Update 20039 505-514. (https://doi.org/10.1093/ humupd/dmg044)

38 Amato MC, Guarnotta V, Ciresi A, Modica R, Pantò F \& Giordano C. No phenotypic differences for polycystic ovary syndrome (PCOS) between women with and without type 1 diabetes mellitus. Journal of Clinical Endocrinology and Metabolism 201499 203-211. (https://doi. org/10.1210/jc.2013-2669)

39 Asch SM, McGlynn EA, Hiatt L, Adams J, Hicks J, DeCristofaro A, Chen R, LaPuerta P \& Kerr EA. Quality of care for hypertension in the United States. BMC Cardiovascular Disorders 20055 1. (https:// doi.org/10.1186/1471-2261-5-1)

40 de Medeiros SF, Gil-Junior AB, Barbosa JS, Isaias ED \& Yamamoto MMW. New insights into steroidogenesis in normo- and hyperandrogenic polycystic ovary syndrome patients. Arquivos Brasileiros de Endocrinologia e Metabologia 201357 437-444. (https:// doi.org/10.1590/s0004-27302013000600005)

41 Matthews DR, Hosker JP, Rudenski AS, Naylor BA, Treacher DF \& Turner RC. Homeostasis model assessment: insulin resistance and beta-cell function from fasting plasma glucose and insulin concentrations in man. Diabetologia 198528 412-419. (https://doi. org/10.1007/bf00280883)

42 Friedwald WT, Levy RI \& Friedrickson DS. Estimation of the concentration of low-density lipoprotein cholesterol in plasma, without use of preparative ultracentrifuge. Clinical Chemistry 197218 499-502.

43 Sowers M, Derby C, Jannausch ML, Torrens JI \& Pasternak R. Insulin resistance, hemostatic factors, and hormone interactions in pre- and perimenopausal women: SWAN. Journal of Clinical Endocrinology and Metabolism 200388 4904-4910. (https://doi.org/10.1210/jc.2003030350)

44 Li L, Yang D, Chen X, Chen Y, Feng S \& Wang L. Clinical and metabolic features of polycystic ovary syndrome. International Journal of Gynaecology and Obstetrics 200797 129-134. (https://doi. org/10.1016/j.ijgo.2007.01.005)

$45 \mathrm{Yu} \mathrm{Ng}$ EH \& Ho PC. Polycystic ovary syndrome in Asian women. Seminars in Reproductive Medicine 200826 14-21. (https://doi. org/10.1055/s-2007-992920)

46 Chan JL, Kar S, Vanky E, Morin-Papunen L, Piltonen T, Puurunen J, Tapanainen JS, Maciel GAR \& Hayashida Jr SAY. Racial and ethnic differences in the prevalence of metabolic syndrome and its components of metabolic syndrome in women with polycystic ovary syndrome: a regional cross-sectional study. American Journal of Obstetrics and Gynecology 2017217 189.e2-189.e8. (https://doi. org/10.1016/j.ajog.2017.04.007)

47 Ukkola O, Gagnon J, Rankinen T, Thompson PA, Hong Y, Leon AS, Rao DC, Skinner JS, Wilmore JH \& Bouchard C. Age, body mass index, race and other determinants of steroid hormone variability: the HERITAGE Family Study. European Journal of Endocrinology 2001 145 1-9. (https://doi.org/10.1530/eje.0.1450001)

48 Lasley BL, Santoro N, Randolf JF, Gold EB, Crawford S, Weiss G, McConnell DS \& Sowers MF. The relationship of circulating dehydroepiandrosterone, testosterone, and estradiol to stages of the menopausal transition and ethnicity. Journal of Clinical Endocrinology and Metabolism 200287 3760-3767. (https://doi.org/10.1210/ jcem.87.8.8741)

49 Kumar A, Woods KS, Bartolucci AA \& Azziz R. Prevalence of adrenal androgen excess in patients with the polycystic ovary syndrome (PCOS). Clinical Endocrinology 200562 644-649. (https://doi. org/10.1111/j.1365-2265.2005.02256.x)

50 Wan S \& Alvero R. Radical and ethnic differences in physiology and clinical symptoms of polycystic ovary syndrome. Seminars in Reproductive Medicine 201331 365-369. (https://doi. org/10.1055/s-0033-1348895)

51 Ding T, Hardiman PJ, Petersen I, Wang FF, Qu F \& Baio G. The prevalence of polycystic ovary syndrome in reproductive-aged women of different ethnicity: a systematic review and meta- 
analysis. Oncotarget 20178 96351-96358. (https://doi.org/10.18632/ oncotarget.19180)

52 Panidis D, Tziomalos K, Papadakis E, Chatzis P, Kandaraki EA, Tsourdi EA, Macut D, Bjekic-Macut J, Marthopoulos A \& Katsikis I. Associations of menstrual cycle irregularities with age, obesity and phenotype in patients with polycystic ovary syndrome. Hormones 201514 431-437. (https://doi.org/10.14310/horm.2002.1593)

53 Oppermann K, Fuchs SC \& Spritzer PM. Ovarian volume in pre-and perimenopausal women: a population-based study. Menopause 2003 10 209-213. (https://doi.org/10.1097/00042192-200310030-00006)

54 Pavlik EJ, DePriest PD, Gallion HH, Ueland FR, Reedy MB, Kryscio RJ \& van Nagell Jr JR. Ovarian volume related to age. Gynecologic Oncology 200077 410-412. (https://doi.org/10.1006/gyno.2000.5783)

55 Pasquali R, Gambineri A, Anconetani B, Vicennati V, Colitta D, Caramelli E, Casimirri F \& Morselli-Labate AM. The natural history of the metabolic syndrome in young women with the polycystic ovary syndrome and the effect of long-term oestrogen-progestagen treatment. Clinical Endocrinology 199950 517-527. (https://doi. org/10.1046/j.1365-2265.1999.00701.x)

56 Yildiz BO, Woods KS, Stanczyk F, Bartolucci A \& Azziz R. Stability of adrenocortical steroidogenesis over time in healthy women and women with polycystic ovary syndrome. Journal of Clinical Endocrinology and Metabolism 200489 5558-5562. (https://doi.org/10.1210/jc.2004-0934)

57 Dewailly D, Catteau-Jonard S, Reyss AC, Leroy M \& Pigny P. Oligoanovulation with polycystic ovaries but not overt hyperandrogenism. Journal of Clinical Endocrinology and Metabolism 200691 3922-3927. (https://doi.org/10.1210/jc.2006-1054)

58 Welt CK, Arason G, Gudmundsson JA, Adams J, Palsdóttir H, Gudlaugsdóttir G, Ingadóttir G \& Crowley WF. Defining constant versus variable phenotypic features of women with polycystic ovary syndrome using different ethnic groups and populations. Journal of Clinical Endocrinology and Metabolism 200691 4361-4368. (https:// doi.org/10.1210/jc.2006-1191)

59 Pehlivanov B \& Orbetzova M. Characteristics of different phenotypes of polycystic ovary syndrome in a Bulgarian population. Gynecological Endocrinology 200723 604-609. (https://doi. org/10.1080/09513590701536246)

60 Gluszak O, Stopinska-Gluszak U, Glinicki P, Kapuscinska R, Snochowska H, Zgliczynski W \& Debski R. Phenotype and metabolic disorders in polycystic ovary syndrome. ISRN Endocrinology 2012 2012 569862. (https://doi.org/10.5402/2012/569862)

61 Moran L \& Teede H. Metabolic features of the reproductive phenotypes of polycystic ovary syndrome. Human Reproduction Update 200915 477-488. (https://doi.org/10.1093/humupd/dmp008)

62 Glintborg D, Mumm H, Ravn P \& Andersen M. Age associated differences in prevalence of individual Rotterdam criteria and metabolic risk factors during reproductive age in 446 Caucasian women with polycystic ovary syndrome. Hormone and Metabolic Research 201244 694-698. (https://doi.org/10.1055/s-0032-1304608)

63 Legro RS, Gnatuk CL, Kunselman AR \& Dunaif A. Changes in glucose tolerance over time in women with polycystic ovary syndrome: a controlled study. Journal of Clinical Endocrinology and Metabolism 2005 90 3236-3242. (https://doi.org/10.1210/jc.2004-1843)

64 Nestler JE Insulin regulation of human ovarian androgens. Human Reproduction 199712 (Supplement 1) 53-62. (https://doi. org/10.1093/humrep/12.suppl_1.53)

65 Macut D, Micić D, Parapid B, Cvijović G, Sumarac M, Kendereski A, Milić N, Tulić L, Muharemagić A, Zorić S, et al. Age and body mass related changes of cardiovascular risk factors in women with polycystic ovary syndrome. Vojnosanitetski Pregled 200259 593-599. (https://doi.org/10.2298/vsp0206593m)
66 Pinola P, Piltonen TT, Puurunen J, Vanky E, Sundström-Poromaa I, Stener-Victorin E, Ruokonen A, Puukka K, Tapanainen JS \& Morin-Papunen LC. Androgen profile through life in women with polycystic ovary syndrome: a Nordic Multicenter Collaboration Study. Journal of Clinical Endocrinology and Metabolism 2015100 3400-3407. (https://doi.org/10.1210/jc.2015-2123)

67 Rashidi BH, Gorginzadeh M, Aalipour S \& Sills ES. Age related endocrine patterns observed in polycystic ovary syndrome patients vs. ovulatory controls: descriptive data from a university based infertility center. Archives of Endocrinology and Metabolism $2016 \mathbf{6 0}$ 486-491. (https://doi.org/10.1590/2359-3997000000215)

68 Azziz R, Rittmaster RS, Fox LM, Bradley Jr EL, Potter HD \& Boots LR. Role the ovary in the adrenal androgen excess of hyperandrogenic women. Fertility and Sterility 199869 851-859. (https://doi. org/10.1016/s0015-0282(98)00033-8)

69 Puurunen J, Piltonen T, Jaakkola P, Ruokonen A, Morin-Papunen L \& Tapanainen JS. Adrenal androgen production capacity remains high up to menopause in women with polycystic ovary syndrome. Journal of Clinical Endocrinology and Metabolism 200994 1973-1978. (https:// doi.org/10.1210/jc.2008-2583)

70 Azziz R \& Koulianos G. Adrenal androgens and reproductive ageing in females. Seminars in Reproductive Medicine 19919 249-260. (https://doi.org/10.1055/s-2007-1019416)

71 Moran C, Knochenhauer E, Boots LR \& Azziz R. Adrenal androgen excess in hyperandrogenism: relation to age and body mass. Fertility and Sterility 199971 671-674. (https://doi.org/10.1016/s00150282(98)00536-6)

72 Qin KN \& Rosenfield RL. Role of cytochrome P450c17 in polycystic ovary syndrome. Molecular and Cellular Endocrinology 1998145 111-121 111-121. (https://doi.org/10.1016/s0303-7207(98)00177-4)

73 Nelson VL, Legro RS, Strauss JF III \& McAllister JM. Augmented androgen production is a stable steroidogenic phenotype of propagated theca cells from polycystic ovaries. Molecular Endocrinology 199913 946-957. (https://doi.org/10.1210/ mend.13.6.0311)

74 Richards JS, Ren YA, Candelaria N, Adams JE \& Rajkovic A. Ovarian follicular theca cell recruitment, differentiation, and impact on fertility: 2017 update. Endocrine Reviews 201839 1-20. (https://doi. org/10.1210/er.2017-00164)

75 Hugues JN, Massart P \& Cedrin-Durnerin I. Assessment of theca cell function: a prerequisite to androgen or luteinizing hormone supplementation in poor responders. Fertility and Sterility 201399 333-336. (https://doi.org/10.1016/j.fertnstert.2012.09.041)

76 Hebert J. The age of dehydroepiandrosterone. Lancet $1995 \mathbf{3 4 5}$ 1193-1194. (https://doi.org/10.1016/s0140-6736(95)91987-2)

77 Ravaglia G, Forti P, Maioli F, Boschi F, Bernardi M, Pratelli L, Pizzoferrato A \& Gasbarrini G. The relationship of dehydroepiandrosterone sulfate (DHEAS) to endocrine-metabolic parameters and functional status in the oldest-old. Results from an Italian study on healthy free-living over-ninety-year-olds. Journal Clinical Endocrinology Metabolic 199681 1173-1178. (https://doi. org/10.1210/jcem.81.3.8772596)

78 Parker CR, Mixon RL, Brissie RM \& Grizzle WE. Aging alters zonation in the adrenal cortex of men. Journal of Clinical Endocrinology and Metabolism 199782 3898-3901. (https://doi.org/10.1210/ jcem.82.11.4507)

79 Piltonen T, Koivunen R, Perheentupa A, Morin-Papunen L, Ruokonen A \& Tapanainen JS. Ovarian age-related responsiveness to human chorionic gonadotropin in women with polycystic ovary syndrome. Journal of Clinical Endocrinology and Metabolism 200489 3769-3775. (https://doi.org/10.1210/jc.2003-031851) https://ec.bioscientifica.com https://doi.org/10.1530/EC-19-0496 (c) 2020 The authors Published by Bioscientifica Ltd
Received in final form 17 December 2019

Accepted 23 December 2019

Accepted Manuscript published online 6 January 2020 